\title{
The Attitude of Female Pediatricians Towards Birth, Breastfeeding and Child Care on Their Own Children in Turkey
}

\author{
๑ Özlem Bağ1, ๑ Utku Karaarslan2
}

1University of Health Sciences, İzmir Dr. Behçet Uz Children's Diseases and Surgery Training and Research Hospital, Clinic of Social Pediatrics, İzmir, Turkey 2University of Health Sciences, İzmir Dr. Behçet Uz Children's Diseases and Surgery Training and Research Hospital, Clinic of Pediatrics, İzmir, Turkey

\begin{abstract}
Aim: Although pediatricians are one of the leading professionals in public to consult with on childbearing, breastfeeding and child care, there is a lack of data about the attitude, choice and practice of pediatricians towards these issues. The aim of this study is to determine female pediatricians' practices on childbearing, breastfeeding and child care and to discuss the possible differences from the general population.

Materials and Methods: This is a descriptive study of women pediatricians' attitudes who have children between 2 and 6 years old, about childbearing, breastfeeding and child care. The study group was surveyed about their demographic characteristics; breastfeeding practices and their general attitude toward mothering. The data were compared with the general population and similar groups in terms of education and socioeconomic status, previously reported in Turkey Demographic and Health Survey in 2013 (TDHS-2013).

Results: The study group included 146 women pediatricians (mean age: $35.49 \pm 3.4$ ) mothering children between 2 and 6 years [median age 3.5 (1.5)] The median age at first birth of the study group [30 (4)] was significantly higher than in the general population. The rate of caesarean delivery of the study group was $91.8 \%$ and was significantly higher than reported previously. The median duration of exclusive and total breastfeeding were 5 (2) months and 13 (11) months respectively. The median duration of exclusive breastfeeding was significantly higher while the total breastfeeding duration was significantly lower than both groups reported in TDHS-2013.

Conclusion: Women pediatricians' choices on and experiences of childbearing, breastfeeding and child care differ from the general population in Turkey. This specific group of health professionals' decisions must be well evaluated worldwide as they have an undeniable role on families, on children and thus on public health.

Keywords: Pediatricians, female, childbearing, breastfeeding, child care
\end{abstract}

\section{Introduction}

Women in the work life have increased in both medical training and practice (1). Female physicians are more likely to practice in primary care fields and to pay more attention to preventive services, health education counselling and the psychosocial needs of their patients (2-4). Pediatrics and pediatric subspecialties are one of the most often practiced fields for female physicians $(5,6)$. Although pediatricians spend most of their daily practice on childbearing, breastfeeding and child care, there is lack of data about the attitudes, choices and practices of female pediatricians concerning these issues. Considering that physicians can act as role models (7), it is important to describe pediatricians' experiences and choices with their own children. The aim of this study is to determine women pediatricians' practices on

\section{Address for Correspondence}

Özlem Bağ MD, University of Health Sciences, İzmir Dr. Behçet Uz Children's Diseases and Surgery Training and Research Hospital, Clinic of Social Pediatrics, İzmir, Turkey Phone: +90 5056274218 E-mail: bagozlem78@yahoo.com ORCID ID: orcid.org/0000-0003-2178-4695 Received: 019.12.2017 Accepted: 28.02.2018 
childbearing, breastfeeding and child care and to discuss the differences from the general population.

\section{Materials and Methods}

\section{Design, Setting and Participants}

The study was designed as a descriptive study of women pediatricians' attitude as mothers in Turkey. Women pediatricians, including general and specialists, pediatric researchers and educators were chosen as the study group. Those mothers with children younger than 2 years old were excluded in order to evaluate total breastfeeding time and those with children older than 6 years old were excluded to assure the data collected was up-to-date. Totally, 596 women pediatricians were interviewed face to face or by mail as to whether they had children between 2 and 6 years and 146 women with children in the defined age range were surveyed. The mothers were included as participants for only their younger child if they had more than one. Those mothers who stated that they do not recall the relevant matters before or during the survey were excluded from the study. The study was approved by the Local Ethics Committee of University of Health Sciences, İzmir Dr. Behçet Uz Children's Diseases and Surgery Training and Research Hospital, Clinic of Social Pediatrics, İzmir, Turkey (approval number: 26.01.2012/9).

\section{Survey Questionnaire}

The questionnaire included demographic characteristics; choices about pregnancy and delivery; breastfeeding and feeding practices and the general attitude toward mothering and personal comment on increased empathy and change of career plans.

\section{Statistical Analysis}

The data were evaluated with SPSS 18 (PASW Statistics for Windows, Version 18.0, Chicago, Illinois, United States of America). Normally distributed data were presented as mean \pm standard deviation, whereas skewed data were presented as median (interquartile range). The data including caesarean section $(C / S)$ rates and breastfeeding durations were compared with available data of both the general Turkish population and a population with similar educational and socioeconomic properties reported in the latest report of Turkey Demographic and Health Survey (TDHS-2013) (8). The difference between the numerical data of the study population were evaluated using the Mann-Whitney $U$ test while the Binomial test was used to evaluate the difference between the numerical data and the data from TDHS-2013. The chi-square test was used to evaluate the difference between proportions. The difference between the proportions of the study group and data in TDHS-2013 were tested with the One Proportion Z test. A p value of $<0.05$ was accepted as significant.

\section{Results}

The study group included 146 pediatricians (mean age $=35.49 \pm 3.4$ ) with children between 2 and 6 years [median age 3.5 (1.5)]. The mean age of the study group at first birth was $30 \pm 3$ years and the median number of children that a mother has was 1 [ minimum $(\min )=1$, maximum $(\max )=3$; interquartile range $(I R)=1]$. Table I presents the sociodemographic data of the study group. The median age at first birth of the study group [30 (4)] was significantly higher than in the general population (median age: $23, \mathrm{p}<0.01$ ) reported in TDHS-2013. The median time spent in pediatrics was 10 years. $62 \%(91 / 146)$ of the study group were general pediatricians while 19\% (28/146) were specialists and 15\% (23/146) were educators of pediatrics. Although there were no pediatric residents in our study group, 63 (43\%) of the participants had had children during residency. The frequency of planned pregnancy was $77 \%$. $94 \%$ of the women were followed up by a gynaecologist during pregnancy. Only 12 (8\%) of the study group performed vaginal delivery. Furthermore, 73\% of caesarean deliveries (C/S) were performed upon maternal request. The rate of C/S of the study group was $91.8 \%$ and was significantly higher than reported in TDHS-2013 for both the general population (48.1\%; $\mathrm{p}<0.01)$ and the population with similar education (66.1\%; $p<0.01$ ) (Table II). The median duration of exclusive breastfeeding and total breastfeeding were 5 (2) months and 13 (11) months, respectively. The data of the study group on exclusive and breastfeeding durations and comparison with TDHS-2013 is exclusive and total breastfeeding given in Table II. The most frequent type of feeding in the first 6 months was exclusively breastfeeding (45\%), followed by predominant breastfeeding (36\%) and mixed feeding with complementary food (19\%). There were no mothers in the study group that had never breastfed but $17(11 \%)$ of the mothers had stopped breastfeeding during the first 6 months for some reason. All of the participants were working at the time of the study. The median duration of maternal leave in the study group was $6(I R=5.5)$ months. Seventy seven (53\%) mothers in the study group returned to work in the first six months after giving birth and the median durations of exclusive and total breastfeeding were significantly lower in this group than for others who returned to work after 6 or more months (median=6 months; $I R=1$ )

\begin{tabular}{|l|l|}
\hline \multicolumn{2}{|l|}{ Table I. The socio-demographic data of the study group } \\
\hline Age $^{*}$ & $35.49 \pm 3.4$ \\
\hline Marital status (married/single) & $144 / 2$ \\
\hline Number of children** & $1(1)$ \\
\hline Age at first birth* & $30.4 \pm 3.1$ \\
\hline Educational status in pediatrics** (years) $^{*}$ & 10 \\
\hline
\end{tabular}

${ }^{*}$ Mean \pm standard deviation, ${ }^{* *}$ Median (interquartile range) 
Table II. The rate of caesarean delivery on maternal request, duration of exclusive and total breastfeeding of the study group and comparison with Turkey Demographic and Health Survey in 2013

\begin{tabular}{|c|c|c|c|c|c|}
\hline & Study group & General population* & p value & Similar population** & $\mathrm{p}$ value \\
\hline CDMR (\%) & 91.8 & 37 & $<0.001$ & $59.5^{b}$ & $<0.001$ \\
\hline Exclusive breastfeeding & 5 & 1.8 & $<0.001$ & $0.6^{\mathrm{b}}$ & $\begin{array}{l}<0.001 \\
<0.001\end{array}$ \\
\hline Total breastfeeding ${ }^{\#}$ & 13 & 15.7 & 0.016 & $16.6^{\mathrm{a}}$ & $\begin{array}{l}0.002 \\
0.002\end{array}$ \\
\hline
\end{tabular}

CDMR: Caesarean delivery on maternal request, *The data of all Turkey Demographic and Health Survey in 2013 population, **The data concerning a population with similar socioeconomic $^{\text {a }}$ and educational ${ }^{b}$ status in Turkey Demographic and Health Survey in 2013, "Median months

$(p=0.02)$. The rate of mothers who stated that their babies were looked after by nannies (not relatives) was 59\% while $39 \%$ of the mothers trusted only grandmothers when they first returned to work after maternal leave. The median time that a mother spent with her child was 3 (2) hours/day. $68 \%$ of the mothers had nobody to help with housework or childcare when they were at home. Nevertheless, $84 \%$ of the mothers stated that their medical knowledge developed after being a mother especially about breastfeeding, weaning and the physical, cognitive and emotional development of children because they experienced what they had previously learned about. Most of the women (98\%) believed that they had an increased sense of empathy towards the children they examine and their families after having a child.

\section{Discussion}

Although it has recently been reported that women have a significant impact in pediatrics (9), there is lack of data about pediatricians' experiences as mothers. There are a few studies reporting the experiences of women physicians as mothers (10-12) but this current study is the first in the literature documenting female pediatricians' attitudes towards the most common issues of pediatric practice; childbearing, breastfeeding and childcare.

\section{Pregnancy and Delivery}

Mothering starts with planning the pregnancy. The frequency of planned pregnancy was $77 \%$ in the study group. Although the median age of the first birth is higher in the study group than reported in TDHS-2013, it is similar with those previously reported in the literature. Sells and Sells (13) reported that the mean age at delivery of a group of women pediatricians in Washington was 29 while Levinson et al. (14) reported a mean age of 30.6 years at the birth of their first child and 32.9 years for their second child. It is known that women physicians make many decisions to shape their path in medicine and determine how to balance home and work (9). The long education period of medical schools and pediatrics are potentially related factors in the study group for the increased age of childbearing. As for the type of delivery, $92 \%$ of the participants had C/S performed while only $8 \%$ performed vaginal delivery. The rate of $C / S$ of the study group was significantly higher than reported in TDHS-2013 for both the general population (48\%; $p<0.001)$ and the population with similar education $(66 \% ; p<0.001)$. In recent years, demographic and health surveys reported from different countries show that there is a considerable increase in the rates of $C / S$, both in developing (15) and developed countries (16). Although the reasons for this remain unclear, defensive medicine due to malpractice lawsuits may be playing a role (17). This also may be a reason in our study group because most of the participants (94\%) were followed up by an obstetrician during pregnancy. Cesarian delivery on maternal request (CDMR), a subset of elective $C / S$, is defined as a $C / S$ for a singleton pregnancy at term in the absence of any medical or obstetric indications, performed only upon maternal request (18). The estimated rate of CDMR is reported to range from $4 \%$ to $18 \%$ of all C/Ss (18). The rate of CDMR in our study group (73\%) is much higher than reported in the literature. Geary et al. (19), has already reported a trend towards a greater number of CDMR among doctors in their relatively small group. As a matter of fact, there are conflicting reports on this issue. Gabbe and Holzman (20) reported that $46 \%$ of a sample of obstetricians personally would prefer C/S while studies from the Netherlands (21) and Israel (22) reported that very few obstetricians would choose $\mathrm{C} / \mathrm{S}$ for themselves or their partners. In a recent report, Finsen et al. (23) reported that the rate of $C / S$ was higher among surgeons (26\%) than among physicians in nonsurgical fields $(18 \%)$ and highest of all among specialists in obstetrics and gynaecology (27\%). The high rate of CDMR in our study group $(73 \%)$ is significantly higher than all groups and represents the highest rate reported in the literature. Although we have not evaluated the reasons for this, we speculate that the training period of pediatricians in neonatal intensive care units and dealing with perinatal asphyxia may be an additional factor in choosing $\mathrm{C} / \mathrm{S}$.

\section{Breastfeeding and Feeding Practices}

The American Academy of Pediatrics recommends exclusive breastfeeding for a min of 4 months, preferably for 6 months and The World Health Organization recommends exclusive breastfeeding up to 6 months of age, with continued 
breastfeeding along with appropriate complementary foods up to two years of age or beyond $(24,25)$. The breastfeeding initiation rate in our study group was 100\% while continuation rates are $88 \%$ and $58 \%$ at 6 months and 12 months respectively; exceeding the rates of the healthy people 2020 goal (82\% ever-breastfed, 61\% at 6 months, and $34 \%$ at 1 year) (26). The rate of exclusive breastfeeding in the study group at 6 months was $66 \%$. In the study group, the median duration of exclusive breastfeeding and total breastfeeding were higher than reported in TDHS-2013. A recent study from Canada reported higher breastfeeding initiation rates among female physicians than the general population (27), similar to our results. As a matter of fact, our results represent the highest rates reported in the literature conducted among female physicians (27-30). However, this study is the only one conducted among female pediatricians. We suggest that although the benefits of human milk are taught during medical teaching, the residency in pediatrics make doctors believe more keenly in breastmilk and this leads to the high initiation rate and long exclusive breastfeeding duration when they become mothers. A recent review provided strong support that $\mathrm{C} / \mathrm{S}$ has a significant negative correlation with early breastfeeding, but if once initiated, rates of breastfeeding at 6 months are not affected by the mode of delivery (32). Our results support that the initiation of breastfeeding is important and suggest that if the mother really intends to breastfeed, the problems brought up with C/S can be overcome. However, the success in continuing breastfeeding depends on other factors including returning to work. Maternal employment has been attributed as a major obstacle to exclusive breastfeeding and breastfeeding continuation for the general population $(32,33)$. Riggins et al. (34) has recently reported that even mothers who are physicians receive inadequate support in the workplace and although they initiate breastfeeding, their breastfeeding rates at 12 months are below the healthy people 2020 goal. In our study group, both exclusive and total breastfeeding durations were significantly lower in those participants who had returned to work before the median time (6 months) than in those returning to work after 6 months $(p=0.02)$. These findings indicate that pediatricians initiate breastfeeding successfully and care about exclusive breastfeeding in the first 6 months due to what they head learnt but cannot overcome the problems facing continued breastfeeding especially after returning to work. All of the women in the study group returned to work at some time after giving birth ( $\min =1.5$ months, $\max =20$ months). The median time of returning to work was 6 (5.5) months in our study group although the duration of maternal leave paid by the government was 2 months. Findings from the Hawkins et al. (35) showed that women working full-time were less likely to initiate breastfeeding and suggested that policies to protect breastfeeding are needed to enable women to choose to delay their return to the workplace. Guendelman et al. (36) showed that short postpartum maternity leave among fulltime working mothers is associated with higher risks of early breastfeeding cessation. Our results support the literature that returning to the workplace influences breastfeeding continuation even if breastfeeding is initiated successfully and also support the current literature that policies are needed to promote breastfeeding in working mothers.

\section{Child Care}

All of the participants were employed and had returned to work after birth. Only $2 \%$ of the mothers preferred day care centres when they first returned to work. Although the type of child care selected is reported to be related with the child and family characteristics as well as maternal attitudes and beliefs (37), it is often necessary to choose other alternatives because of the lack of on-site day care. $59 \%$ of the participants had non-relative carers for their children while $39 \%$ had relatives including grandmothers. There were no children under only their fathers' care in our study group because all of the fathers were working too. The mean time that a mother spent with her child was $3.3 \pm 1.4$ hours/day. $68 \%$ of these mothers had nobody to assist with housework or childcare except for husbands when they were at home. Thus, $76 \%$ of the mothers stated that they could not allow time to study medicine, to read or write medical articles etc in the first year after giving birth while this rate decreased to $38 \%$ in the second year. In addition, 55\% of participants confessed that they had a change in career plans after having a child. These findings show that mothers continue to bear the primary responsibility for child care and housework especially, although $35 \%$ of them reported that their husbands 'help' them in child care. Cooksey et al. (38), reported that dealing with time pressures to assure productivity in workplace and to take care for the family affects mothers negatively. Although employment can lead to the empowerment of women and have a positive effect on child health and well-being $(39,40)$, it has recently been reported that work and family conflict may be a negative risk factor for young children's mental health (41). Both employed mothers including pediatricians and politicians need to be aware of this risk and suggest plans to do the best for mothers and their children to maintain public health (42).

\section{Study Limitations}

The most important limitation of this research is the lack of knowledge about the number of female pediatricians with children between 2-6 years old in Turkey, thus we are not sure of the rate of the study sample we have covered. Statistics on doctors from the Ministry of Health do not include the active status of their children's age and number, thus it was not possible to obtain the required data. The only way was to survey female pediatricians. The second limitation is the recall element as the study concept depends on a retrospective 
design although the mothers who stated that they did not recall were excluded from the study. Further studies prospectively conducted with this group will help to understand the attitudes of pediatricians when they become mothers.

\section{Conclusion}

Female paediatricians with children are a specific group of women physicians and it is important to understand their decisions about childbearing, breastfeeding and child care because they have an undeniable role on families, on children and thus on public health. The very high rate of CDMR among pediatricians is remarkable and the reasons for this must be evaluated to understand and reduce the rate of CDMR. The higher rate of exclusive breastfeeding among pediatricians than both the general population and other female physicians is also remarkable and shows that knowledge about and belief in breastfeeding is an important issue. However, female pediatricians need to be supported to balance home and work in order to maintain their continued presence in the pediatric work force so that they do not have to choose between their children and their careers as both should be possible.

\section{Ethics}

Ethics Committee Approval: The study was approved by the Local Ethics Committee of University of Health Sciences, İzmir Dr. Behçet Uz Children's Diseases and Surgery Training and Research Hospital, Clinic of Social Pediatrics, İzmir, Turkey (approval number: 26.01.2012/9).

Informed Consent: Not applicable due to the study design.

Peer-review: Internally peer-reviewed.

\section{Authorship Contributions}

Surgical and Medical Practices: Ö.B., U.K., Concept: Ö.B., U.K., Design: Ö.B., U.K., Data Collection and Processing: U.K., Analysis and Interpretation: Ö.B., U.K., Literature Search: Ö.B., Writing: Ö.B.

Conflict of Interest: No conflict of interest was declared by the authors.

Financial Disclosure: The authors declared that this study received no financial support.

\section{References}

1. Association of American Medical Colleges. Women in U.S. Academic Medicine: Statistics and Benchmarking, 2008-2009. www.aamc.org/download/53454/data/figure2 2009.pdf (accessed November 14), 2011.

2. Delgado A, Lorez-Fernandez LA, Luna JD. Influence of the doctor's gender in the satisfaction of users. Med Care 1993;31:795-800

3. Lurie N, Slater I, McGovern P, Ekstrum I, Quam L, Margolis K. Preventive care for women. Does the sex of the physician matter? N Engl J Med 1993;329:478-82.
4. Kreuter MW, Streches VI, Harris R, Robin SC, Skinner CS. Are patients of women physicians screened more aggressively? A prospective study of physician gender and screening? I Gen Intern Med 1995;10:119-25.

5. Women Chairs of the Association of Medical School Pediatric Department Chairs. Women in pediatrics: recommendations for the future. Pediatrics 2007;119:1000-5.

6. McMurray JE, Linzer M, Konrad TR, Douglas I, Shugerman R, Nelson K. The Work Lives of Women Physicians Results from the Physician Work Life Study. The SCIM Career Satisfaction Study Group. J Gen Intern Med 2000;15:372-80.

7. Althouse LA, Stritter FT, Steiner BD. Attitudes and approaches of influential role models in clinical education. Adv Health Sci Educ Theory Pract 1999;4:111-22.

8. Hacettepe University Institute of Population Studies. 2013 Turkey Demographic and Health Survey. Hacettepe University Institute of Population Studies, T.R. Ministry of Development and TÜBITAK, Ankara, Turkey, 2014.

9. Barkin SL, Fuentes-Afflick E, Brosco JP, Tuchman AM. Unintended consequences of the Flexner report: women in pediatrics. Pediatrics 2010;126:1055-7.

10. Walsh $A$, Gold $M$, Jensen $P$, Jedrzkiewicz M. Motherhood during residency training: challenges and strategies. Can Fam Physician 2005;51:990-1.

11. Duke PS, Parsons WL, Snow PA, Edwards AC. Physicians as mothers: breastfeeding practices of physician-mothers in Newfoundland and Labrador. Can Fam Physician 2007;53:88791.

12. Sattari M, Levine D, Serwint JR. Physician mothers: an unlikely high risk group-call for action. Breastfeed Med 2010;5:35-9.

13. Sells JM, Sells C). Pediatrician and parent: a challenge for female physicians. Pediatrics 1989;84:355-61.

14. Levinson W, Tolle SW, Lewis C. Women in academic medicine. Combining career and family. N Engl J Med 1989;321:1511-7.

15. Stanton CK, Holtz SA. Levels and trends in cesarean birth in the developing world. Stud Fam Plann 2006;37:41-8.

16. Martin JA, Hamilton BE, Ventura SJ, Osterman MJ, Wilson EC Mathews TJ. Births: final data for 2010. Natl Vital Stat Rep 2012;61:1-72

17. No authors listed. Caesarean section on the rise. Lancet 2000;356:1697.

18. No authors listed. National Institutes of Health state-of-thescience conference statement: Cesarean delivery on maternal request March 27-29, 2006. Obstet Gynecol 2006;107:1386-97.

19. Geary M, Wilshin J, Persaud M, Hindmarsh PC, Rodeck CH. Do doctors have an increased rate of Caesarean section? Lancet 1998;351:1177.

20. Gabbe SG, Holzman GB. Obstetricians' choice of delivery. Lancet 2001;357:722.

21. van Roosmalen J. Elective caesarean section on request. Unnecessary caesarean sections should be avoided. BMJ 1999;318:121.

22. Gonen R, Tamir A, Degani S. Obstetricians' opinion regarding patient choice in cesarean delivery. Obstet Gynecol 2002;99:577-80.

23. Finsen $V$, Storeheier $A H$, Aasland OG. Cesarean section: Norwegian women do as obstetricians do--not as obstetricians say. Birth 2008;35:117-20.

24. Gartner LM, Morton J, Lawrence RA, et al. Breastfeeding and the use of human milk. Pediatrics 2005;115:496-506.

25. http://www.who.int/topics/breastfeeding/en/ 
26. US Department of Health and Human Services. (2013). Healthy People 2020: Breastfeeding objectives. http:/www.usbreastfeeding.org / LegislationPolicy/FederalPoliciesInitiatives/ HealthyPeople2020BreastfeedingObjectives/tabid/120/ Default.aspx.

27. Duke PS, Parsons WL, Snow PA, Edwards AC. Physicians as mothers: breastfeeding practices of physician-mothers in Newfoundland and Labrador. Can Fam Physician 2007;53:88791.

28. Miller N, Miller D, Chism M. Breastfeeding practies among resident physicians. Pediatrics 1996;98:434-7.

29. Arthur CR, Saenz RB, Replogle WH. The employmentrelated breastfeeding decisions of physician mothers. I Miss State Med Assoc 2003;44:383-7.

30. Kacmar JE, Taylor JS, Nothnagle M, Stumpff J. Breastfeeding practices of resident physicians in Rhode Island. Med Health R I. 2006;89:230-1.

31. Prior E, Santhakumaran S, Gale C, Philipps LH, Modi N, Hyde MJ. Breastfeeding after cesarean delivery: a systematic review and meta-analysis of world literature. Am J Clin Nutr 2012;95:111335.

32. Skafida V. Juggling work and motherhood: the impact of employment and maternity leave on breastfeeding duration: a survival analysis on Growing Up in Scotland data. Matern Child Health I 2012;16:519-27.

33. Ogbuanu C, Glover S, Probst J, Hussey I, Liu J. Balancing work and family: effect of employment characteristics on breastfeeding. I Hum Lact 2011;27:225-38.
34. Riggins $C$, Rosenman MB, Szucs KA. Breastfeeding experiences among physicians. Breastfeed Med 2012;7:151-4.

35. Summer S. Hawkins, Lucy J. Griffiths, Carol Dezateux, Catherine Law and The Millennium Cohort Study Child Health Group.

36. Hawkins SS, Griffiths L), Dezateux C, Law C; Millennium Cohort Study Child Health Group. Maternal employment and breastfeeding initiation: findings from the Millennium Cohort Study. Paediatr Perinat Epidemiol. 2007;21:242-7

37. Sylva K, Stein A, Leach P, Barnes J, Malmberg LE; FCCC-team. Effects of early child-care on cognition, language, and taskrelated behaviours at 18 months: an English study. $\mathrm{Br}$ / Dev Psychol 2011;29:18-45.

38. Cooksey E, Joshi H, Verropoulou G. Does mothers' employment affect children's development? Evidence from the children of the British 1970 Birth Cohort and the American NLSY79. Longitudinal Life Course Stud 2009;1:95-115.

39. Charmarbagwala $R$, Ranger $M$, Waddington $H$, et al. The determinants of child health and nutrition: a meta-analysis: World Bank. 2004. http://ieg.worldbankgroup.org/Data/ reports/ child_health_nutrition.pdf

40. Carnes M, Morrissey C, Geller SE. Women's health and women's leadership in academic medicine: hitting the same glass ceiling? I Womens Health (Larchmt) 2008;17:1453-62.

41. Strazdins L, Obrien LV, Lucas N, Rodgers B. Combining work and family: rewards or risks for children's mental health? Soc Sci Med 2013;87:99-107.

42. Women Chairs of the Association of Medical School Pediatric Department Chairs. Women in pediatrics: recommendations for the future. Pediatrics 2007;119:1000-5. 